\title{
Estimation of Midblock Median Opening U-Turn Roadway Capacity Based on Sectioning Method
}

\author{
Johnnie Ben-Edigbe \\ Department of Civil Engineering, School of Engineering, University of KwaZulu-Natal, Durban 4041, South Africa \\ Correspondence should be addressed to Johnnie Ben-Edigbe; ben-edigbe@ukzn.ac.za
}

Received 28 October 2015; Accepted 11 January 2016

Academic Editor: Binggen Zhang

Copyright ( 2016 Johnnie Ben-Edigbe. This is an open access article distributed under the Creative Commons Attribution License, which permits unrestricted use, distribution, and reproduction in any medium, provided the original work is properly cited.

\begin{abstract}
Capacity definition recognises that only traverse point or uniform section of roadway capacity can be estimated. Since midblock median U-turn opening is a nonuniform infrastructure, a novel capacity estimation method is needed. The paper proposes sectioning models for estimating U-turn capacity based on dynamics and regression theory. Surveyed U-turn roadway was divided into three sections (entry, middle curve, and exit). Traffic data for each section and adjoining priority traffic stream were collected continually for eight weeks. After modifying passenger car values, ensuing traffic flows and computed densities were used to develop capacity model for entry and middle curve. Regression models where traffic flows from the exit section were taken as the dependent variables and flows from the priority stream were taken as independent variable were used to model capacity for the exit section. Sensitivity analysis shows that the proposed models can produce reliable and accurate results. Results reveal that that traffic capacity at entry $(1221 \mathrm{pcu} / \mathrm{h}$ ) and exit (about $350 \mathrm{pcu} / \mathrm{h}$ ) sections differs significantly. The paper concluded that U-turn roadway capacity cannot be generalized because the structure is nonuniform.
\end{abstract}

\section{Introduction}

In previous studies many methods have been proposed to estimate median U-turn opening capacity. Highway Capacity Manual (HCM) 2010 gap acceptance is one of the most important components in microscopic traffic characteristic and critical headway is a key parameter. Gap acceptance models are widely in many studies to describe traffic behaviour at "give way" junctions on the premises that drivers in the nonpriority streams decide whether to join the priority stream based on time gaps between priority stream successive vehicles. These time gaps are assumed to follow a given headway distribution. The problem is not the procedure but the interpretation of the ensuing outcomes. Capacity is defined in HCM 2010 as the maximum number of vehicles that can pass through a point or uniform section of carriageway lane in one direction per hour under prevailing roadway, traffic, or ambient conditions. Since median U-turn opening is a nonuniform structure, capacity cannot be estimated singularly. The nonuniform structure has to be divided into sections before capacity can be computed without violating capacity definition. It can be argued. Probabilistic model based on gap acceptance theory was put forward by Drew [1]. Lertworawanich and Elefteriadou [2] developed a new gap acceptance model by redefining expressway capacity. AlMasaeid [3] developed a linear regression model as well as gap acceptance model to estimate capacity of U-turn movement and concluded that gap acceptance model gave a better capacity estimate. Al-Masaeid [3] also indicated that the gap acceptance models would provide unrealistic capacity values even if critical gaps and move-up times were estimated for local conditions. Liu et al. [4] conceded that HCM gap acceptance model may not reflect the behaviour of motorists in countries outside the United States. Interestingly, none of the previous studies mentioned the need to modify passenger car equivalent values and also that the estimated capacity is not a U-turn capacity but exit section capacity. Directional midblock median U-turn opening facilities found in some countries are used exclusively for vehicle detour at road segments. The facilities are usually made up of two straight and a curved middle sections. Unlike conventional median opening with multilegs intersection, these 


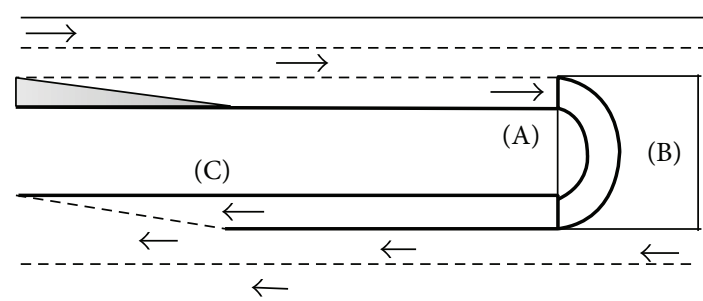

FIGURE 1: Typical midblock median U-turn openings facilities.

unsignalised facilities permit vehicles to make a complete Uturn on separate channelized roadway without connection to other junction. Vehicles enter the U-turn roadway with steadily reduced speed and search priority traffic stream for a safe exit merging gap. On arrival at the exit section, drivers make their intentions known to the priority stream by moving sometimes menacingly to the taper end of the exit lane. Priority vehicles may allow the merge to occur, increase speed, change lane to avoid collusion, honk horn, flash headlight, or simply ignore the nonpriority vehicle altogether. At peak period merging from the exit point becomes a deft maneuver and daring affair. Since midblock median U-turn opening is a nonuniform infrastructure, a novel capacity estimation method is needed. Based on the hypothesis that sectioning method would provide acceptable capacities for nonuniform roadways irrespective of the number of turns, the study objective was to develop sectioning models that take cognisant of the nonuniform shape of midblock median opening facilities. Consequently, theoretical arguments are presented in the next section. In Section 3 traffic data collection and analysis are presented. Findings and discussions are the focus of Section 4 and conclusions are drawn in the last section.

\section{Theoretical Background}

In many countries (Malaysia, Nigeria, and South Africa), directional midblock median U-turn openings are exclusive facilities at road segments meant for U-turn movement only. They are meant to ease traffic pressure at intersections located some distance away from the facilities. These facilities are not to be confused with median opening at highway intersections. Typical midblock median U-turn opening has three sections, entry, middle curvature, and exit. Vehicles entering the facilities decelerate gradually on approach and continue at lower speed until it is safe at the exit to merge with priority traffic stream. As shown in Figure 1, midblock median Uturn opening is a nonuniform structure. Since the midblock median opening facilities have three sections (entry, middle curvature, and exit), capacity estimation method is dependent on the section of interest. After all, capacity represents the maximum sustainable hourly flow rate at which vehicles reasonably can be expected to traverse a point or a uniform section of a lane or roadway during a given time period under prevailing roadway, environmental, traffic, and control conditions. The key words are point and uniform. As stated in HCM 2010, vehicles are expected to traverse a point or uniform section of a roadway. Therefore it would be null and void to compute capacity of a nonuniform roadway singularly irrespective of how it was done. When estimating the capacity of a nonuniform roadway irrespective of method used, it is essential that such a structure is divided into uniform sections before computing sectional capacities. Since the midblock median U-turn opening has three sections, capacity for each section was dependent on prevailing conditions. Capacities at entry and middle curvature sections can be computed as traverse point section where the exit section must take cognizance of priority traffic stream. In any case, modification of passenger car equivalent values is encouraged irrespective of capacity estimation method used. Since PCE measures the impact that a mode of transport has on traffic variables compared to a passenger car under prevailing conditions, it follows that changes in prevailing conditions will have relative effect on PCE values. In essence PCE values are dynamic.

2.1. Dynamics of Passenger Car Equivalent Values. The term "passenger car equivalent" was defined in Highway Capacity Manual (HCM) 2010 as "the number of passenger cars displaced in the traffic flow by truck or a bus under the prevailing roadway and traffic conditions." This definition still holds today and the use of such equivalents is central to road capacity analysis where mixed traffic stream is present. Ignoring PCE modifications could lead to questionable capacity outputs. Previous studies have been silent on this issue. According to Seguin et al. [5] and Ben-Edigbe [6], notwithstanding the method adopted, modified passenger car equivalent values will have no effect on the outcome of the study. So, there is no need to build a new one. In the paper, a simple headway method shown below as (1) was used:

$$
\mathrm{PCE}_{i}=\frac{H_{i}}{H_{c}}
$$

where $\mathrm{PCE}_{i}$ is the passenger car unit of vehicle class $i, H_{i}$ is the average headway of vehicle class $i$, and $H_{c}$ is the average headway of passenger car.

\subsection{Capacity Model For U-Turn at Entry and Middle Cur-} vature Sections. Capacity at entry and middle section can be estimated as traverse point by way of maximum volume, headway methods, and speed, flow, and density relationships taking cognizance of uniformity. According to Minderhoud et al. [7] the capacity estimation problem consists of a series of essential points of interest and capacity estimation method varies accordingly. Within the purview of fundamental relationship between flow, speed, and density, capacity is reached at the apex of the curve $(Q)$ as shown in Figure 2.

Capacity for any traverse point along entry and middle curve sections can be estimated using model equation

$$
q=-c+a k-b k^{2} \longrightarrow \frac{\partial q}{\partial k}=a-2 b k=0 \longrightarrow k_{c}=\frac{a}{2 b}
$$

In theory, where the flow/density curve is used to compute capacity, density is extrapolated mathematically till the maximum of the flow/density function is reached. It has been 


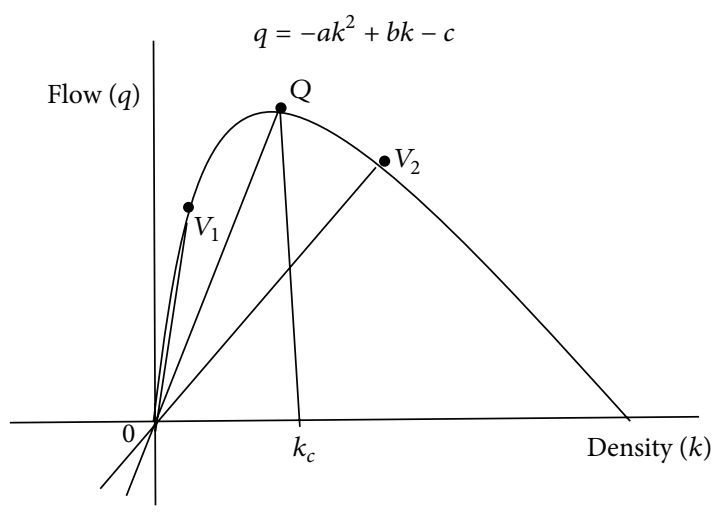

Figure 2: Hypothetical flow and density curve.

shown that capacity can be computed with (3) below, BenEdigbe et al. [8]:

$$
\text { Capacity, } \begin{aligned}
Q= & -c+(a) \frac{u_{f}}{2\left(u_{f} / k_{j}\right)} \\
& -b\left(\frac{u_{f}}{2\left(u_{f} / k_{j}\right)}\right)^{2},
\end{aligned}
$$

where $V_{1}$ and $V_{2}$ are speed points on the curve, $q$ is flow $(\mathrm{pcu} / \mathrm{hr}), u$ is speed $(\mathrm{km} / \mathrm{hr}), k_{c}$ is density at capacity (veh $/ \mathrm{km}), u_{f}$ is free-flow speed, $k_{j}$ is jam density, and $c$ is a constant.

2.3. Capacity Model for U-Turn at Exit Section. Capacity at the exit section of midblock median U-turn opening is dependent on merging gaps along the priority traffic stream. So, it can be estimated using regression techniques or gap acceptance theory. Regression analysis is a technique used for modelling and analysis of numerical data consisting of values of a dependent variable (response variable) and of one or more independent variables (explanatory variables). The dependent variable in the regression equation is modelled as a function of the independent variables, corresponding parameters (constants), and an error term. The error term is treated as a random variable. It represents unexplained variation in the dependent variable. The parameters are estimated so as to give a "best fit" of the data. Assumptions of linear regression modelling are as follows: sample must be representative of the population for the inference prediction; dependent variable is subject to error; independent variable is error-free; predictors must be linearly independent; errors are uncorrelated; variance of the error is constant; errors follow a normal distribution. Since traffic flow at the exit section C of the U-turn roadway is considered to be nonpriority stream, then capacity can be estimated using

$$
Q_{p}=q_{m}-\gamma Q_{a}+\varepsilon
$$

where $Q_{p}$ denotes capacity of nonpriority traffic stream, $\gamma=$ $Q_{p} / Q_{a}$ and $\varepsilon$ are error terms, $q_{m}$ denotes maximum flow, and $Q_{a}$ denotes capacity of priority traffic stream.
Al-Masaeid [3] developed regression model shown below to estimate capacity of U-turn movements at unsignalised median openings:

$$
C=1545-790 e^{q_{c} / 3600},
$$

where $C$ is capacity of $\mathrm{U}$-turn movements (veh/h) and $q_{c}$ is conflicting traffic flow (veh/h).

Al-Masaeid [3] estimated U-turn capacity singularly which is a clear violation of capacity uniformity rule. Secondly, the regression model relies on priority stream headway as independent model instead of priority stream flows. AlMasaeid [3] assumes that regression slope is a function of delay and also indicated that the gap acceptance models would provide unrealistic capacity values even if critical gaps and move-up times were estimated for local conditions in Jordan. Gap acceptance is the minimum gap required to finish lane changing safely. It is an important parameter that describes how a driver judges whether to accept or not merging gaps. The critical gap is defined by Kyte et al. [9] as the minimum gap in the major traffic stream needed by a minor stream vehicle to merge into or travel through the major stream gap. HCM defines the critical gap as the "minimum length time interval that allows intersection entry to one minor street vehicle." The critical gap values measured by different people may be inconsistent, depending on the interpretation of "what is the minimum gap size"? The Siegloch [10] capacity model, which is used in the German guidelines, assumes a negative exponential model of arrival headways. Using Siegloch's formula the capacity for nonpriority traffic stream can be estimated as

$$
Q=\left(3600 / t_{m}\right) e^{-p^{\left[t_{c}-\left(t_{m} / 2\right)\right]}},
$$

where $Q$ is capacity of nonpriority stream (veh/h), $p=$ $q / 3,600, t_{c}$ is critical gap (s), $q$ is priority traffic stream, $t_{m}$ is move-up time (s), and $e$ is base of the natural logarithm.

In HCM, (7) is used as the basis to determine the capacity and level of service of a minor traffic stream at an unsignalised intersection under ideal conditions. According to Kimber [11] gap acceptance models are poor predictors of the capacity of nonpriority streams in the United Kingdom; hence probability concept was introduced in (8) and used in HCM to estimate U-turn capacity of median opening. However, no attempt was made to separate the U-turn roadway into sections which is a clear violation of capacity uniformity rule:

$$
C_{p, x}=q_{c, x} \frac{e^{-q_{c, x} t_{c, x} / 3600}}{1-e^{-q_{c, x} t_{f, x} / 3600}},
$$

where $C_{p, x}$ is potential capacity of minor movement $x$ (veh/h), $q_{c, x}$ is conflicting flow rate for movement $x$ (veh/h), $t_{c, x}$ is critical gap for minor movement $x$, and $t_{f, x}$ is follow-up time for minor movement $x$. Consider

$$
\begin{aligned}
Q_{p} & =\sum_{n=1}^{\infty}\left\{v _ { c } \left[P\left(h>t_{c}+(n-1) t_{f}\right)\right.\right. \\
& \left.\left.-P\left(h>t_{c}+n_{t_{f}}\right) n\right]\right\},
\end{aligned}
$$


TABLE 1: Priority and nonpriority traffic stream data.

\begin{tabular}{|c|c|c|c|c|c|c|c|c|c|}
\hline \multirow{3}{*}{ Hourly Period } & \multicolumn{6}{|c|}{ Priority traffic stream } & \multicolumn{3}{|c|}{ U-turn traffic stream } \\
\hline & \multicolumn{4}{|c|}{ Skudai, Malaysia } & \multicolumn{2}{|c|}{ Durban, South Africa } & \multirow[b]{2}{*}{$\begin{array}{l}\text { Flow } \\
\text { pcu/h }\end{array}$} & \multirow[b]{2}{*}{$\begin{array}{l}\text { Speed } \\
\mathrm{km} / \mathrm{h}\end{array}$} & \multirow[b]{2}{*}{$\begin{array}{l}\text { Density } \\
\text { veh } / \mathrm{km}\end{array}$} \\
\hline & Flow $^{1}$ & Hwy (s) & Flow $^{2}$ & Hwy (s) & Flow $^{3}$ & Hwy (s) & & & \\
\hline 1 & 2234 & 1.61 & 1489 & 2.42 & 1579 & 2.28 & 349 & 23 & 15.17 \\
\hline 2 & 2037 & 1.77 & 1358 & 2.65 & 1515 & 2.38 & 393 & 24 & 16.38 \\
\hline 3 & 2046 & 1.76 & 1364 & 2.64 & 1485 & 2.42 & 449 & 27 & 16.63 \\
\hline 4 & 2300 & 1.57 & 1533 & 2.35 & 1585 & 2.27 & 336 & 23 & 14.61 \\
\hline 5 & 2441 & 1.47 & 1627 & 2.21 & 1717 & 2.10 & 210 & 18 & 11.67 \\
\hline 6 & 2139 & 1.68 & 1426 & 2.52 & 1523 & 2.36 & 378 & 26 & 14.54 \\
\hline 7 & 2184 & 1.65 & 1456 & 2.47 & 1494 & 2.41 & 401 & 24 & 16.71 \\
\hline 8 & 2246 & 1.60 & 1497 & 2.40 & 1482 & 2.43 & 442 & 29 & 15.24 \\
\hline 9 & 2019 & 1.78 & 1346 & 2.67 & 1384 & 2.60 & 499 & 27 & 18.48 \\
\hline 10 & 2453 & 1.47 & 1635 & 2.20 & 1673 & 2.15 & 263 & 21 & 12.52 \\
\hline 11 & 2376 & 1.52 & 1584 & 2.27 & 1632 & 2.21 & 301 & 22 & 13.68 \\
\hline 12 & 2099 & 1.72 & 1399 & 2.57 & 1346 & 2.67 & 544 & 29 & 18.76 \\
\hline
\end{tabular}

${ }^{1}$ Peak.

${ }^{2,3}$ Off-peak.

where $Q_{p}$ is potential capacity, $v_{c}$ is conflicting traffic flow rate, $P(h>t)$ is probability that the headway is larger than $t, t_{c}$ is critical headway, $t_{f}$ is follow-up headway, and $n$ is $\mathrm{U}$ turn vehicles in the same headway.

\section{Data Collection and Analysis}

The studies were carried out in Skudai, Malaysia, and Durban, South Africa. Typically, U-turn roadway was divided into three sections A (entry), B (mid-curvature), and C (exit). Traffic volumes, speeds, vehicle types, and headways data were collected continuously for eight weeks. Traffic volumes were converted to flow using modified passenger car equivalent values and used in conjunction with travel speeds to derive densities. Traffic data collected in Skudai, Malaysia, were used to develop sectional models and those collected in Durban, South Africa, were used for model validations. As shown in Table 1 about fifty thousand vehicles were surveyed and processed. Average hourly traffic flow for priority stream was $2,215 \mathrm{pcu} / \mathrm{h}$ peak and $1476 \mathrm{pcu} / \mathrm{h}$ off peak. 85 percentile speed is about $88 \mathrm{~km} / \mathrm{h}$. Average peak headway $=1.63 \mathrm{~s}$ and Off-peak $=2.44 \mathrm{~s}$. Average traffic flow from Uturn movement was $380 \mathrm{pcu} / \mathrm{h}$ with an average headway of $9.5 \mathrm{~s}$ and 85 percentile speed of about $28 \mathrm{~km} / \mathrm{h}$.

Traffic flows (col.8) and densities (col.10) were used to develop model for transverse points at sections A and B. The model coefficients in (9) shown in Figure 3 have the expected signs and the coefficients of determinations $\left(R^{2}\right)$ are much greater than 0.85 , it can be suggested that a strong relationship between flows and densities exists and the model could be used to estimate roadway sectional capacity. The $F$ observed statistics at 10 degrees of freedom is much greater than $F$ critical (4.94) suggesting that the relationship did not occur by chance. Also the $t$-observed statistic at 10 degrees of

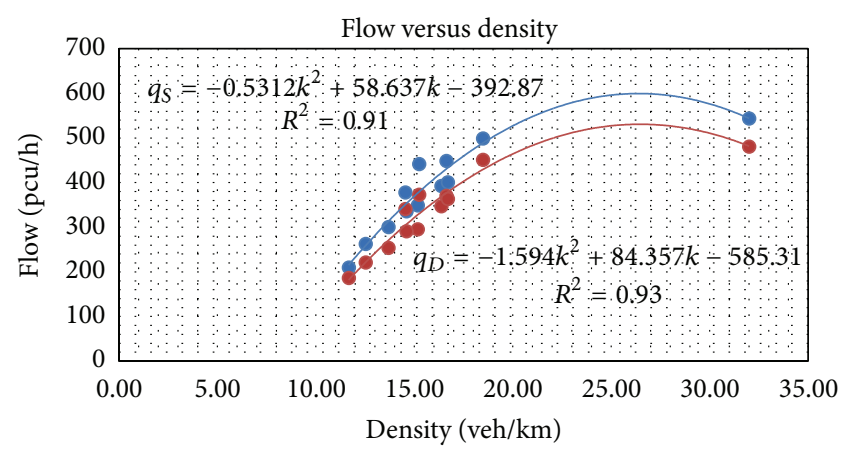

Figure 3: Skudai $\left(q_{S}\right)$ and Durban $\left(q_{D}\right)$ nonpriority traffic stream models.

freedom tested at $5 \%$ significance level is greater than 2 . The model equation is shown in Figure 3:

$$
\begin{aligned}
q & =-0.5312 k^{2}+56.637 k-392.87 \quad R^{2}=0.91, \\
\frac{\partial q}{\partial k} & =-1.062 k+56.563=0 \\
k & =55 \mathrm{veh} / \mathrm{km} \longrightarrow q=1211 \mathrm{pcu} / \mathrm{h} ; \quad v=22 \mathrm{~km} / \mathrm{h} .
\end{aligned}
$$

From (9) density at capacity $(k)=55 \mathrm{veh} / \mathrm{km}$, capacity $(q)$ $=1211 \mathrm{pcu} / \mathrm{h}$, and speed at capacity $(v)=22 \mathrm{~km} / \mathrm{h}$. Based on sectioning method, the capacity of U-turn roadway at entry and middle curvature sections is about $1211 \mathrm{pcu} / \mathrm{h}$.

Capacity at U-turn exit section can be estimated by way of linear regression where priority traffic stream flows $\left(q_{c}\right)$ are the independent variables and traffic flows at the exit section are the dependent variables. Hourly traffic flows at 


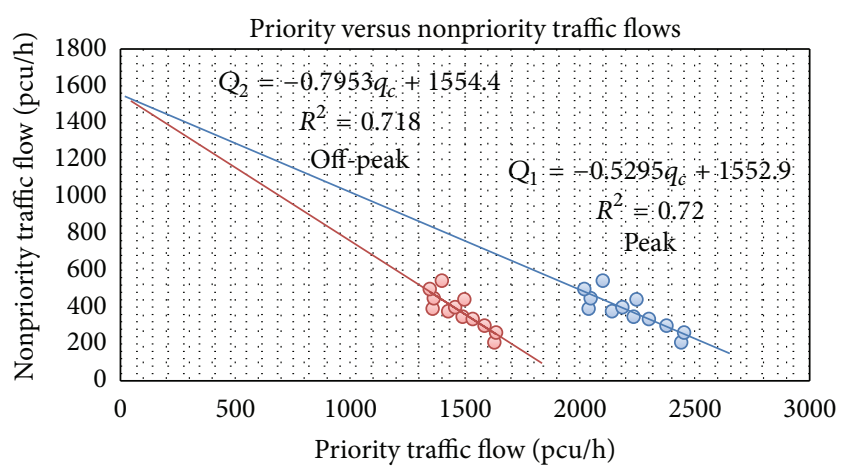

FIgURE 4: Linear regression models for exit sections C.

exit section $\mathrm{C}$ and priority traffic flows were used to develop exit capacity model equations for section C (see Figure 4).

Peak Exit Capacity. Consider

$$
Q_{1}=1553-0.5293 q_{c} \quad R^{2}=0.72 .
$$

Off-Peak Exit Capacity. Consider

$$
Q_{2}=1554-0.7953 q_{c} \quad R^{2}=0.72 .
$$

Both models are reasonably in good fit with $R^{2}$ value of 0.72 . The $F$-observed statistics at 10 degrees of freedom is much greater than $F$ critical (4.94) suggesting that the relationship did not occur by chance. Also the $t$-observed statistic at 10 degrees of freedom tested at $5 \%$ significance level is much greater than 2. As shown in Figure 4, when priority stream traffic flow is set at zero, exit capacity is $1553 \mathrm{veh} / \mathrm{h}>1211 \mathrm{veh} / \mathrm{h}$, thus confirming the workability of the midblock median U-turn opening push and pull system. It means that all vehicles entering the facilities can exit when the priority traffic stream flow is between zero and $500 \mathrm{pch} / \mathrm{h}$ or $750 \mathrm{pcu} / \mathrm{h}$. The average headway at priority stream is about $6 \mathrm{~s}$. Even though peak and off-peak data were used, the maximum traffic flow through the midblock median U-turn opening is about $1550 \mathrm{pcu} / \mathrm{h}$, thus highlighting limitations inherent in the structural U-shape design of the facilities.

\section{Discussions}

Three arching issues were presented in this paper; firstly, midblock median opening is a nonuniform structure since uniform roadway section means that the shape and size are the same; secondly capacity cannot be estimated for nonuniform roadway structure without sectioning; and thirdly, the dynamics of passenger car equivalency is an instrument of capacity estimation. Since U-turn roadway structure is not a uniform section, capacity cannot be estimated singularly; to suggest otherwise will clearly violate the definition of capacity. That explains why the sectioning is the best estimation method. The midblock median opening facilities surveyed were divided into three uniform sections before capacities were computed using appropriate methods. Entry, middle curvature, and exit sections were treated exclusively. On approach to midblock median opening facilities, vehicles diverge to gain access to U-turn opening facilities and merge with priority traffic stream when exiting. As shown in Table 1, priority stream traffic data collected at median opening facilities in Durban, South Africa, were used to validate sectioning method. Since previous studies computed capacity for exit section of the median opening sectioning method was validated against exit capacity based on critical gap and regression method as shown in Table 2.

Al-Masaeid regression model [3] used priority stream headways as independent variables. Nevertheless, it predicted an exit capacity not a U-turn capacity of $1545 \mathrm{veh} / \mathrm{h}$ when priority traffic stream flow is at zero. When priority traffic stream was at $1535 \mathrm{pcu} / \mathrm{h}$ both Ben-Edigbe sectioning method and Al-Masaeid regression models predicted $330 \mathrm{pcu} / \mathrm{h}$ exit capacity. Statistical analysis suggests that both exit capacities are the same. Sectioning method allows for entry capacity to be ascertained and also useful measurement of traffic flow reliability at exit section. As for Harder's [12] gap acceptance method the estimated U-turn exit capacity is $573 \mathrm{veh} / \mathrm{h}$ as shown in Table 2. Gap acceptance and headway methods made no provision for entry capacity estimation and wrongly treated U-turn structure as a single entity. As shown in Table 2 findings regarding exit-straight capacity (BenEdigbe's and Al-Masaeid's: 1533 pcu/hr and 1545 pcu/hr, resp.) and capacity when circulating flow is at maximum (BenEdigbe's and Al-Masaeid's: 333 pcu/hr and $335 \mathrm{pcu} / \mathrm{hr}$, resp.) have consistent values even though their estimation methods are different. It must be mentioned that gap acceptance method has exaggerated capacity compared to sectioning and regression methods.

\section{Conclusions}

This study developed capacity for midblock median U-turn opening based on sectioning method by way of dividing the roadway into 3 sections with uniform shapes and sizes before computing capacity per section using appropriate methods. Capacity for entry and middle curvature sections was computed from flow and density model, whereas capacity for the exit section was based on regression model with priority traffic stream being the independent variable and nonpriority traffic stream the dependent variable. Based on the findings and discussions in the paper, the following can be concluded.

(i) U-turn roadway or any other roadway with turns must be divided into uniform sections because capacity can be estimated per section based on prevailing conditions.

(ii) Capacity estimation for U-turn must take into consideration the dynamics of passenger car equivalency and modify the values as appropriate.

(iii) Where traffic flow is being influenced by priority stream, regression model can give a good estimate of nonpriority stream capacity. 
TABLE 2: Comparable outcomes of singular and multiple capacity methods.

\begin{tabular}{lccc}
\hline U-turn sections & Methods & Harder's gap acceptance \\
\hline Entry-straight & $1221 \mathrm{pcu} / \mathrm{h}$ & N/A \\
Middle curve & $1221 \mathrm{pcu} / \mathrm{h}$ & N/A & N/A \\
Exit-straight $\left(q_{c}=0\right)$ & $1553 \mathrm{pcu} / \mathrm{h}$ & $\mathrm{N} / \mathrm{A}$ & $\mathrm{N} / \mathrm{A}$ \\
Exit $\left(q_{c}=1535 \mathrm{pcu} / \mathrm{h}\right)$ & $333 \mathrm{pcu} / \mathrm{h}$ & $1545 \mathrm{veh} / \mathrm{h}$ & $573 \mathrm{veh} / \mathrm{h}$ \\
\hline
\end{tabular}

(iv) Capacity at the exit section of median opening based on gap acceptance model provides reasonable but considerably higher results.

(v) The hypothesis that sectioning model would provide acceptable capacities nonuniform roadways is valid.

\section{Conflict of Interests}

The author declares that there is no conflict of interests regarding the publication of this paper.

\section{Acknowledgments}

This research is supported by the University of KwaZuluNatal, Durban, South Africa, and Transportation Infrastructure Research Group and Road Safety Research Group.

\section{References}

[1] D. R. Drew, Gap Acceptance in the Freeway Merging Process, vol. 208 of Highway Research Record, 1967.

[2] P. Lertworawanich and L. Elefteriadou, "A methodology for estimating capacity at ramp weaves based on gap acceptance and linear optimization," Transportation Research Part B: Methodological, vol. 37, no. 5, pp. 459-483, 2003.

[3] H. R. Al-Masaeid, "Capacity of U-turn at median opening," ITE Journal, vol. 69, no. 6, pp. 28-34, 1999.

[4] P. Liu, J. J. Lu, F. Hu, and G. Sokolow, "Capacity of U-turn movement at median openings on multilane highways," Journal of Transportation Engineering, vol. 134, no. 4, pp. 147-154, 2008.

[5] E. Seguin, K. Crowley, and W. Zweig, Passenger Car Equivalents on Urban Freeways Interim Report@, Contract DTFH61-C00100, Institute for Research (IR), State College, Pa, USA, 1998.

[6] J. Ben-Edigbe, "Assessment of speed-flow-density functions under adverse pavement condition," International Journal of Sustainable Development and Planning, vol. 5, no. 3, pp. 238252, 2010.

[7] M. M. Minderhoud, H. Botma, and P. H. Bovy, "Assessment of roadway capacity estimation methods," Transportation Research Record: Journal of the Transportation Research Board, vol. 1572, no. 1, pp. 59-67, 1997.

[8] J. Ben-Edigbe, H. Alhassan, and S. Aminu, "Selective estimations of empirical roadway capacity, Journal of Engineering \& Applied Sciences, vol. 8, no. 1, pp. 71-76, 2013.

[9] M. Kyte, M. Dixon, and P. M. Basavaraju, "Why field measurements differ from model estimates: analysis framework for capacity and level-of-service analysis of unsignalised intersections," Transportation Research Record, vol. 1852, pp. 32-39, 2013.
[10] W. Siegloch, "Capacity evaluation at unsignalized intersections," Strassenbau und Strassenverkehrstechnik 154, Bundesminister für Verkehr, Bonn, Germany, 1973.

[11] R. M. Kimber, "Gap-acceptance and empiricism in capacity prediction," Transportation Science, vol. 23, no. 2, pp. 100-111, 1989.

[12] J. Harders, The Capacity of Unsignalised Urban Intersections, vol. 76 of Schriftenreihe Strassenbau Strassenverkehrstechnik, 1968. 


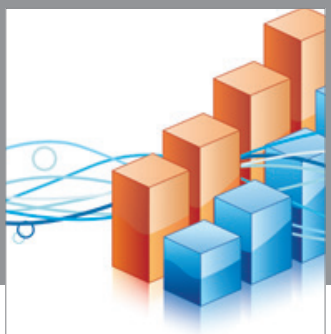

Advances in

Operations Research

vatem alat4

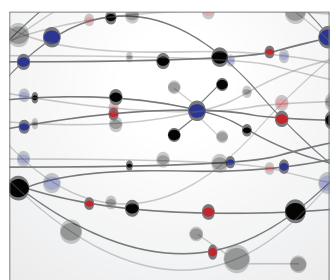

\section{The Scientific} World Journal
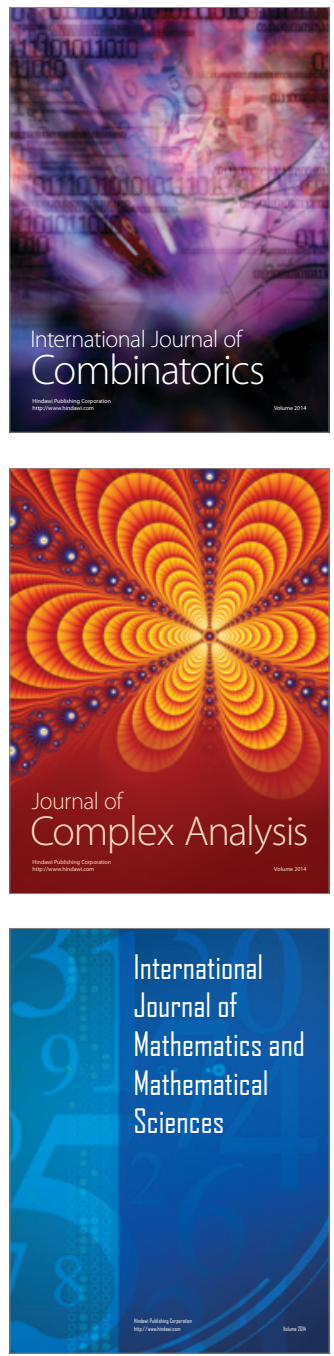
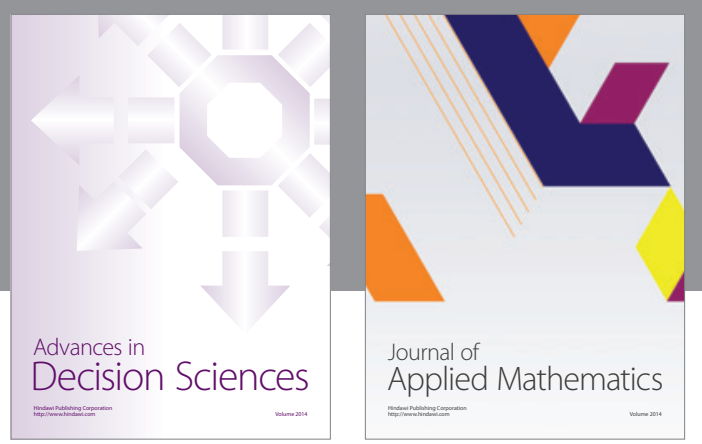

Algebra

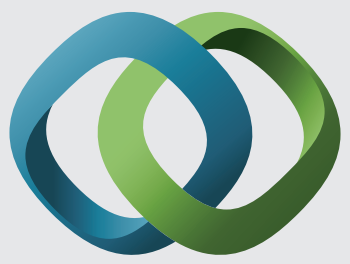

\section{Hindawi}

Submit your manuscripts at

http://www.hindawi.com
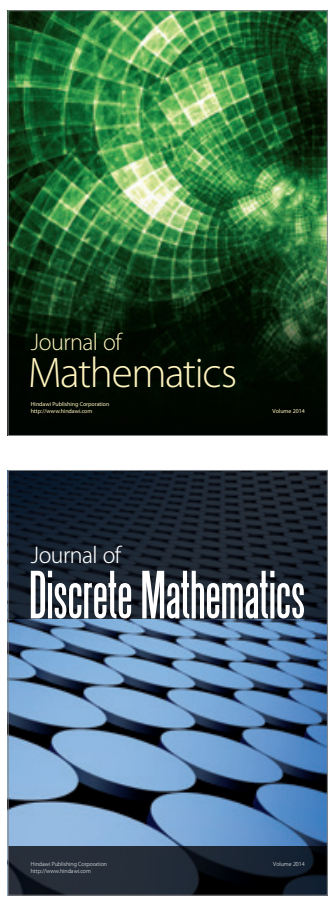

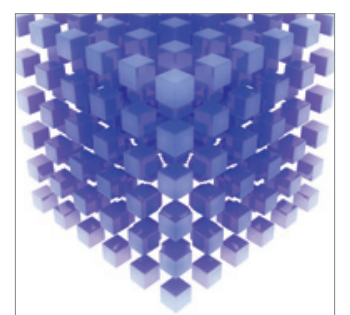

Mathematical Problems in Engineering
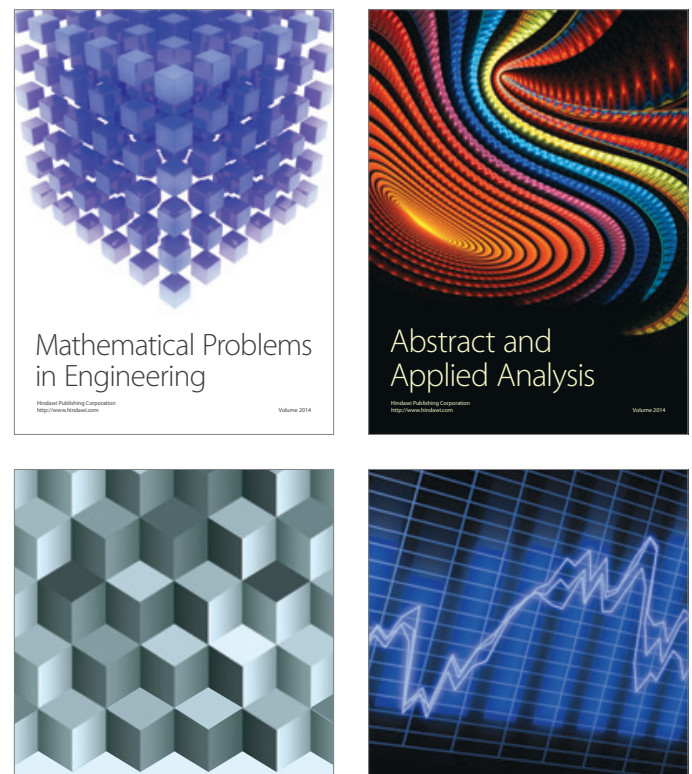

Journal of

Function Spaces

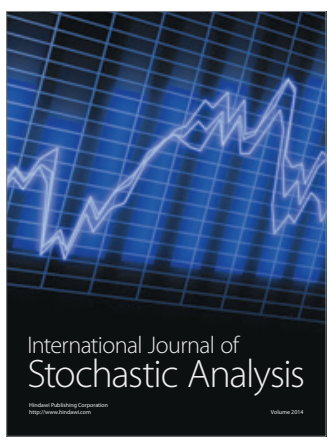

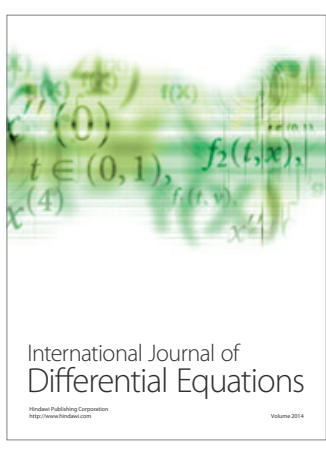
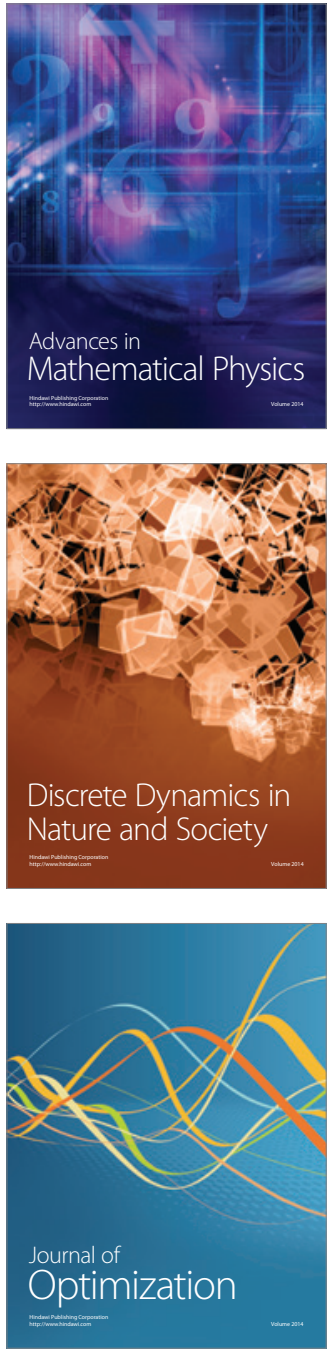